\title{
Association between single nucleotide polymorphisms in the p53 pathway and response to radiotherapy in patients with nasopharyngeal carcinoma
}

\author{
XIAOXUE XIE ${ }^{1}$, HEKUN JIN $^{1}$, JUN HU ${ }^{2}$, YONG ZENG $^{3}$, JUMEI ZHOU ${ }^{1}$, SHUYU OUYANG ${ }^{1}$, \\ WENJUAN YANG ${ }^{1}$, BINGQIANG HU ${ }^{1}$ and $\mathrm{HUI} \mathrm{WANG}^{1}$ \\ Departments of ${ }^{1}$ Radiation Oncology, ${ }^{2}$ Pathology, and ${ }^{3}$ Clinical Pharmacology Research Base, \\ Hunan Provincial Tumor Hospital and Affiliated Tumor Hospital of Xiangya Medical School, \\ Central South University, Changsha, Hunan 410013, P.R. China
}

Received July 30, 2013; Accepted September 13, 2013

DOI: $10.3892 /$ or.2013.2808

\begin{abstract}
Single nucleotide polymorphisms (SNPs) in the p53, MDM2 and p21 genes of the p53 pathway have been extensively studied. The main aim of the current retrospective study was to evaluate the possible predictive value of SNPs in the p53 pathway in locoregionally advanced nasopharyngeal carcinoma (NPC) in response to radiotherapy. In total, 75 consecutive patients with locoregionally advanced NPC were enrolled. Three SNPs in the p53 pathway were identified using the Sanger sequencing method from retrospectively collected paraffin-embedded biopsy specimens. The effects of genetic polymorphisms on patient progression-free survival (PFS) were analyzed using the Cox proportional hazards model, Kaplan-Meier method and log-rank test. All of the selected subjects completed questionnaires on smoking habits prior to treatment. Multivariate analysis showed that the p53 codon 72 Pro/Pro genotype [hazard ratio (HR), $0.300 ; 95 \%$ confidence interval (CI), 0.092-0.983; $\mathrm{P}=0.047]$ and heavy smoking ( $\geq 30$ pack-years) (HR, 2.899; 95\% CI, 1.349-6.229; $\mathrm{P}=0.006$ ) are independent significant prognostic factors for PFS in patients with locoregionally advanced NPC. Moreover, mean times to disease progression for heavy smokers ( $\geq 20$ pack-years) carrying p53 codon 72 Arg/Arg, p21 codon $31 \mathrm{Arg} / \mathrm{Arg}$ and MDM2 309 SNP G/G genotypes were only $14.78 \pm 3.00,11.00 \pm 0.58$ and $11.17 \pm 1.85$ months, respectively. These time scales were less than half of those recorded for patients containing other genotypes and moderate smokers ( $<20$ pack-years). In conclusion, the p53 codon 72 polymorphism is an independent prognostic marker for locoregionally
\end{abstract}

Correspondence to: Dr Hui Wang, Department of Radiation Oncology, Hunan Provincial Tumor Hospital and Affiliated Tumor Hospital of Xiangya Medical School, Central South University, 283 Tongzipo Road, Changsha, Hunan 410013, P.R. China E-mail: wanghui710327@163.com

Key words: nasopharyngeal carcinoma, single nucleotide polymorphisms, p53 pathway, radiotherapy, smoking advanced NPC. Moreover, analysis of SNPs in the p53 pathway may facilitate the identification of patients at high risk of poor disease outcome in subgroups of heavy smokers.

\section{Introduction}

Upon cellular stress, the p53 protein is stabilized to regulate the expression, cellular location and activity of key effectors of cellular processes, such as DNA repair, cell cycle arrest, senescence and apoptosis. The p53 tumor-suppressor pathway plays a central role in reducing cancer frequency and mediating response to commonly used cancer therapies. The most frequently studied single nucleotide polymorphisms (SNPs) in the p53 pathway have been identified in the p53, MDM2 and p21 genes (p53 codon 72, rs1042522, G/C; MDM2 SNP309, rs2279744, T/G; p21 codon 31, rs1801270, C/A). However, meta-analyses are required to further highlight the predictive power of these SNPs. The present study was designed to evaluate the predictive value of SNPs in the p53 pathway in response to radiotherapy using biopsy specimens of locoregionally advanced nasopharyngeal carcinoma (NPC) obtained before treatment.

Different alleles of proline (p53-codon 72-Pro) and arginine (p53-codon 72-Arg) were initially reported in 1988 by Buchman and colleagues (1). The amino acid encoded by codon 72 resides in a polyproline region of p53 located between the transactivation and DNA-binding domains. This proline-rich region has been shown to be important for p53 function, in particular, its ability to induce apoptosis. Several studies to date have provided evidence that the two different p53 isoforms encoded by codon 72 SNPs are not functionally equivalent (2-6). For example, Vannini et al (7) showed that metastatic breast cancer patients homozygous for Arg have a significantly shorter time to progression and overall survival (OS) than those with heterozygous Arg/Pro tumors. Kim et al (8) reported that the Arg/Pro and Pro/Pro genotypes of TP53 codon 72 are significantly correlated with a lower response rate to combination chemotherapy, compared to the Arg/Arg genotype, in advanced gastric cancer patients. Moreover, knowledge of individual genotypes at the p53 
codon 72 locus and p53 mutational status of tumors may facilitate subclassification of patients according to their ability to respond to specific chemotherapeutic agents, allowing determination of the optimal therapeutic strategy. In patients retaining wild-type $\mathrm{p53}$, wtp53-codon 72 -Arg was associated with the best response rates as well as OS and progression-free survival (PFS), concordant with higher apoptotic potential. In patients with mutant p53, mtp53-codon 72-Pro was associated with prolonged OS and PFS, in keeping with its relatively high apoptotic potential, compared with mtp53-codon 72-Arg (9). The p53 gene is rarely mutated in NPC (10), and a metaanalysis (11) showed that individuals with the homozygous Arg/Arg genotype have decreased risk of NPC, compared with those carrying the Pro/Pro genotype. However, the relationship between the TP53 codon 72 polymorphism and clinical outcomes of NPC remains to be elucidated.

MDM2 binds directly to p53 and consequently regulates its transcriptional activation ability, cellular localization and targeting for proteasomal degradation. These observations allow for the possibility that substituting a few (or even a single) base pair(s) in the regulatory regions of the gene alters MDM2 activity sufficiently to affect the p53 pathway, and therefore, cancer in humans (12). Extensive analysis of a heritable, human genetic variant, in particular, a polymorphism in the MDM2 promoter (MDM2 SNP309 T/G) has lent support to this hypothesis (12-14). Tu et al (15) reported that the MDM2 SNP309 G/G polymorphism is associated with poor OS in advanced oral squamous cell carcinoma (OSCC), and a combination of MDM2 SNP309 G/G and p53 codon 72 Arg/Arg polymorphisms was linked to the poorest OS and PFS. Chaar et al (16) additionally showed a significantly more favorable clinical outcome of the wild-type SNP 309 genotype $(T / T)$ than the genotype $(T / G, G / G)$ in colorectal cancer. Furthermore, a significant association of the MDM2 SNP309 G/G allele with favorable outcomes in female glioblastoma patients was reported by Zawlik et al (17). Zhou et al (18) demonstrated that, compared with the TT genotype, the G allele (GT + GG genotype) is associated with markedly increased susceptibility to NPC and advanced lymph node metastasis. Similarly, Sousa et al (19) reported that the MDM2 SNP309 GG homozygote confers increased risk of NPC development. However, few studies have investigated the predictive or prognostic value of MDM2 SNP309 polymorphisms in response to radiotherapy in patients with local regionally advanced NPC.

The cyclin-dependent kinase (CDK) inhibitor, p21 (CDKN1A), mediates the induction of cell cycle arrest in response to a variety of stimuli, mainly through its ability to inhibit the kinase activities of CDK2 and CDK1 (20-23). The role of p21 in promoting DNA damage-induced G1 growth arrest relies significantly on its well-characterized transcriptional activation by p53 $(22,23)$. The nonsynonymous codon 31 (C/A) SNP in the CDKN1A gene (rs1801270) results in an amino acid change from serine (p21-Ser) to arginine (p21Arg) in a highly conserved region. Similar to p53 codon 72 and MDM2 SNP309, the allelic frequency at this locus varies greatly among populations, from a $4 \%$ prevalence of the Arg allele in a Swedish population to $50 \%$ in Chinese (24). Moreover, the different alleles encoding these variants have been shown to vary considerably in terms of transcriptional efficiency $(25,26)$. Tan et al $(27)$ reported that in TP53 72 Pro breast cancer carriers with the p21 Ser/Ser genotype, the occurrence of acute toxicity induced by radiotherapy is reduced in normal weight, but not overweight patients. Tsai et al (28) showed that the serine form of $\mathrm{p} 21$ codon 31 is more prominent in smokers than non-smokers among NPC patients. The difference between smokers and non-smokers suggests the involvement of an environmental factor in association with the p21 gene in NPC formation. In the present study, upon analysis of the polymorphisms of p53 pathway genes and their impact on response to radiotherapy in patients with locoregionally advanced NPC, smoking was also consistently identified as an important factor.

\section{Materials and methods}

Patient selection. Between January 2008 and October 2009, 75 consecutive patients with locoregionally advanced NPC at the Department of Radiotherapy, Affiliated Tumor Hospital of Xiangya Medical School (Central South University, Changsha, China), were enrolled retrospectively in this study. Patients with biopsy-confirmed previously untreated NPC with American Joint Committee on Cancer (AJCC)/International Union Against Cancer (UICC) stage II, III and IV(A-B) disease were eligible. Other criteria included age $>18$ years, ethnic Han Chinese individuals, and an Eastern Cooperative Oncology Group performance status of 0 or 1 . The exclusion criteria included the presence of distant metastasis and other concomitant malignant disease. The study was approved by the Clinical Research Ethics Committee of the Hunan Province Cancer Center, and written informed consent was obtained from all of the patients. The patient characteristics are summarized in Table I. The participants included 57 male and 18 female patients with a male-to-female ratio of 3.2:1 and a median age of 45 years (range, 22-72 years). All patients were diagnosed with World Health Organization (WHO) grade 2-3 NPC. Overall, 16 patients had stage II, 44 had stage III, and 15 had stage IV(A-B) disease. Questionnaires on smoking habits collected prior to treatment contained information on smoking status, number of cigarettes/day, and number of years of smoking. Pack-year was defined as years of smoking 20 cigarettes/day.

Pretreatment evaluation. Evaluations for all patients included complete physical examination, fiber optic nasopharyngoscopy, magnetic resonance imaging (MRI) of the head and neck, chest X-ray, abdominal imaging with ultrasound and bone scan. All patients were prospectively included in a disease-specific database.

Treatment. Megavoltage photons (6 MV) were used to treat the primary tumor and neck lymph nodes. Radiotherapy was administered five times a week at a dose of 2 Gy/day. The accumulated dose of radiation was 68-72 Gy to the primary tumor, 60-62 Gy to the involved areas of the neck, and $50 \mathrm{~Gy}$ to the uninvolved areas. Concurrent chemoradiotherapy was administered to 39 patients and adjuvant chemoradiotherapy to 40 patients. As concurrent chemoradiotherapy, DDP $\left(100 \mathrm{mg} / \mathrm{m}^{2}\right)$ was administered on days 1,22 and 43 during radiotherapy. 
Table I. Patient demographics and treatment characteristics.

\begin{tabular}{|c|c|}
\hline Characteristics & No. of patients ( $\%$ \\
\hline \multicolumn{2}{|l|}{ Age (years) } \\
\hline Range & $22-72$ \\
\hline Median & 45 \\
\hline \multicolumn{2}{|l|}{ Gender } \\
\hline Male & $57(76.0)$ \\
\hline Female & $18(24.0)$ \\
\hline \multicolumn{2}{|c|}{ Overall stage $(\mathrm{AJCC})^{\mathrm{a}}$} \\
\hline II & $16(21.3)$ \\
\hline III & $44(58.7)$ \\
\hline IVa-b & $15(20.0)$ \\
\hline \multicolumn{2}{|l|}{ T classification $^{\mathrm{a}}$} \\
\hline $\mathrm{T} 1-2$ & $42(56.0)$ \\
\hline T3-4 & $33(44.0)$ \\
\hline \multicolumn{2}{|l|}{$\mathrm{N}_{\text {classification }}{ }^{\mathrm{a}}$} \\
\hline N0 & $16(21.3)$ \\
\hline N1-3 & $59(78.7)$ \\
\hline \multicolumn{2}{|c|}{ Concurrent chemotherapy } \\
\hline No & $36(48.0)$ \\
\hline Yes & $39(52.0)$ \\
\hline \multicolumn{2}{|c|}{ Adjuvant chemotherapy } \\
\hline No & $35(46.7)$ \\
\hline Yes & $40(53.3)$ \\
\hline \multicolumn{2}{|c|}{ Smoking status (pack-years) } \\
\hline 0 & $38(50.7)$ \\
\hline$>0-<20$ & $16(21.3)$ \\
\hline$\geq 20$ & $21(28.0)$ \\
\hline$\geq 30$ & $16(21.3)$ \\
\hline
\end{tabular}

${ }^{a} 7$ th American Joint Committee on Cancer/International Union Against Cancer staging system.

Endpoints. The primary endpoint for the study was PFS, defined as the time from the day of enrollment to the date of first documented relapse, categorized as locoregional (primary site or regional node) failure or distant metastases, or the final follow-up visit.

Sample preparation, DNA extraction and quantification of DNA yield. From each sample, $510-\mu \mathrm{m}$ tissue sections were deparaffinized using xylene and ethanol. Specimens were digested with proteinase $\mathrm{K}$ for $24 \mathrm{~h}$ at $55^{\circ} \mathrm{C}$. Subsequently, the enzyme was inactivated by boiling samples for $10 \mathrm{~min}$ prior to mixing with absolute ethyl alcohol. After purification using ion-exchange columns, genomic DNA was incubated at $-20^{\circ} \mathrm{C}$ before use.

DNA amplification and genotyping procedures. For each assessed polymorphism, the nested polymerase chain reaction (PCR) method was used to amplify specific fragments with the primers listed in Table II. The amplification reaction was performed in three steps: $5 \mathrm{~min}$ at $95^{\circ} \mathrm{C}$, followed by 35 cycles of $30 \mathrm{sec}$ at $95^{\circ} \mathrm{C}, 30 \mathrm{sec}$ at $55^{\circ} \mathrm{C}$ and $40 \mathrm{sec}$ at $72^{\circ} \mathrm{C}$, and $10 \mathrm{~min}$ at $72^{\circ} \mathrm{C}$. PCR products were identified by electrophoresis before Sanger sequencing using BigDye Terminator v3.1 chemistry (Life Technologies, Carlsbad, CA, USA) on an Applied Biosystems 3130xl Genetic Analyzer. All PCR reactions and sequencing analyses were performed twice to confirm the results.

Follow-up. The follow-up period ended on October 31, 2012, with a median follow-up of 25 months (range, 5-46). After completion of treatment, patients were followed up at least every 3 months during the first year, and every 6 months thereafter until disease progression (recurrence or distant metastases). All local recurrences were diagnosed via fiberoptic endoscopy and biopsy and/or MRI of the nasopharynx and the skull base showing progressive bone erosion and/or soft tissue swelling. Regional recurrence was diagnosed based on clinical examination of the neck, and in doubtful cases, fine needle aspiration or MRI of the neck. Distant metastases were diagnosed based on clinical symptoms, physical examination and imaging methods, including chest radiography, abdominal sonography, whole body bone scan, computed tomography (CT) scan and MRI. During follow-up, $22(29.3 \%)$ patients had locoregional relapse while 21 $(28.0 \%)$ displayed distant metastasis. No patients succumbed to the disease during follow-up. The 3-year PFS rate was $42.7 \%$.

Statistical analysis. Demographic and clinical information was compared across genotypes using Pearson's $\chi^{2}$ test (for categorical variables) and one-way ANOVA (for continuous variables), where appropriate. Hardy-Weinberg equilibrium was tested using a goodness-of-fit $\chi^{2}$ test with one degree of freedom. Each genotype was independently analyzed for correlation with survival times. The Kaplan-Meier method was adopted to estimate survival curves, and the log-rank test to compare patient survival times between subgroups. Multivariate analyses using Cox regression were employed to assess the significance of genotypes with adjustment for age, gender, T classification, $\mathrm{N}$ classification, overall stage and chemotherapy. Analyses were carried out using the statistical software package SPSS 17.0 (SPSS, Inc., Chicago, IL, USA). All statistical tests were two-sided, and a value of $\mathrm{P}<0.05$ was considered to indicate a statistically significant result. The Bonferroni correction was applied to adjust primary analysis.

\section{Results}

p53 codon 72 SNP, p21 codon 31 SNP and MDM2 SNP309 were clearly distinguished by sequencing. The typical sequencing peak diagrams that were obtained are depicted in Fig. 1. The Arg allelic frequencies were 0.23 and 0.37 for p53 codon 72 SNP and p21 codon 31 SNP, respectively, and $\mathrm{G}$ allelic frequency was 0.55 for MDM2 SNP309. These frequencies fulfill the Hardy-Weinberg distribution. Table III shows the distribution of SNPs according to clinical variables. Tumor stage was not significantly associated with any of the polymorphisms analyzed. However, the frequency of MDM2 SNP309 $\mathrm{G}$ allele was higher in more advanced disease (T3-4) $(\mathrm{P}=0.001)$.

For tumor stage, only $\mathrm{T}$ classification was significantly associated with the time to disease progression (Fig. 2). However, both $\mathrm{T}$ and $\mathrm{N}$ classification were significantly 
Table II. Primers for nested PCR amplification of the p53 pathway genes.

\begin{tabular}{|c|c|c|}
\hline SNPs & Initial primers & Second primers \\
\hline rs 1042522 & $\begin{array}{l}\text { 5'-GCAAGAAGCCCAGACGG-3' (267 bp) } \\
\text { 5'-CTCTTTTCACCCATCTACAGTC-3' }\end{array}$ & $\begin{array}{l}\text { 5'-GGGAAGGGACAGAAGATG-3' (222 bp) } \\
\text { 5'-CTCTTTTCACCCATCTACAGTC-3' }\end{array}$ \\
\hline rs2279744 & $\begin{array}{l}\text { 5'-GTCGCCGCCAGGGAGGA-3' (338 bp) } \\
\text { 5'-GGGAAAATGCATGGTTTAAATAGCC-3' }\end{array}$ & $\begin{array}{l}\text { 5'-GAGTTCAGGGTAAAGGTCAC-3' (165 bp) } \\
\text { 5'-TCAAGAGGAAAAGCTGAGTC-3' }\end{array}$ \\
\hline rs 1801270 & $\begin{array}{l}\text { 5'-AGGTAACATAGTGTCTAATCTCCG-3' (343 bp) } \\
\text { 5'-CCTGCCTCCTCCCAACTC-3' }\end{array}$ & $\begin{array}{l}\text { 5'-AGGTAACATAGTGTCTAATCTCCG-3' (246 bp) } \\
\text { 5'-CCCTCCAGTGGTGTCTCG-3' }\end{array}$ \\
\hline
\end{tabular}

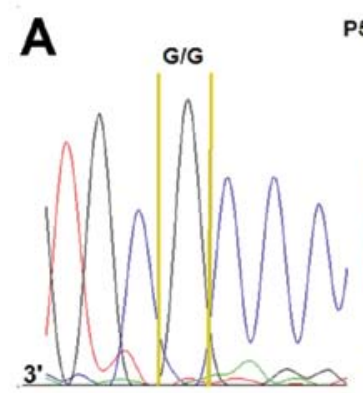

P53 Codon 72 Arg72Pro G>C

B
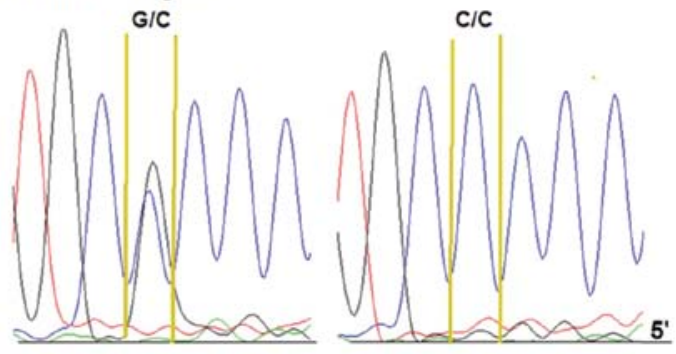

B

MDM2 SNP309 T>G
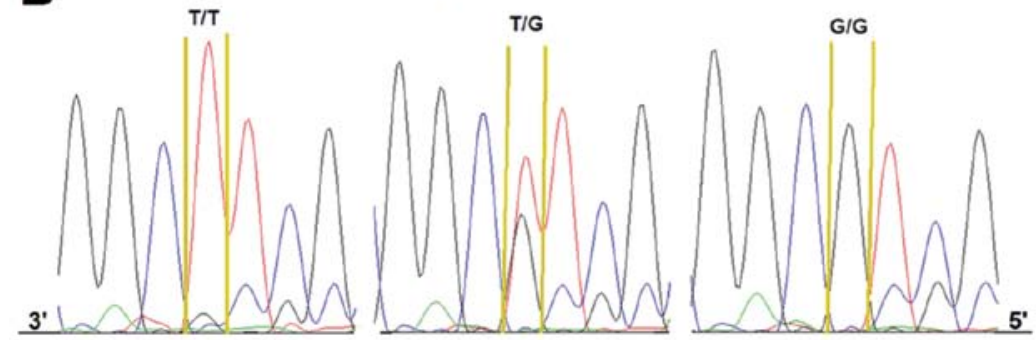

C

P21 Codon31 Ser31Arg C>A

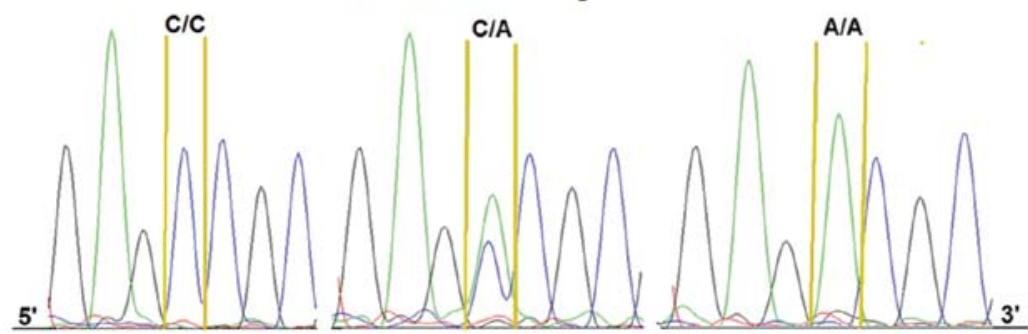

Figure 1. Typical raw data obtained using Sanger sequencing instruments for (A) p53 codon 72 (G>C), (B) MDM2 SNP309 (T>G) and (C) p21 codon 31 (C >A) polymorphisms. The area between the yellow lines indicates the resulting genotypes; p53 codon $72 \mathrm{G}$ equivalent to Arg and C equivalent to Pro; p21 codon 31 $\mathrm{C}$ equivalent to Ser and A equivalent to Arg.
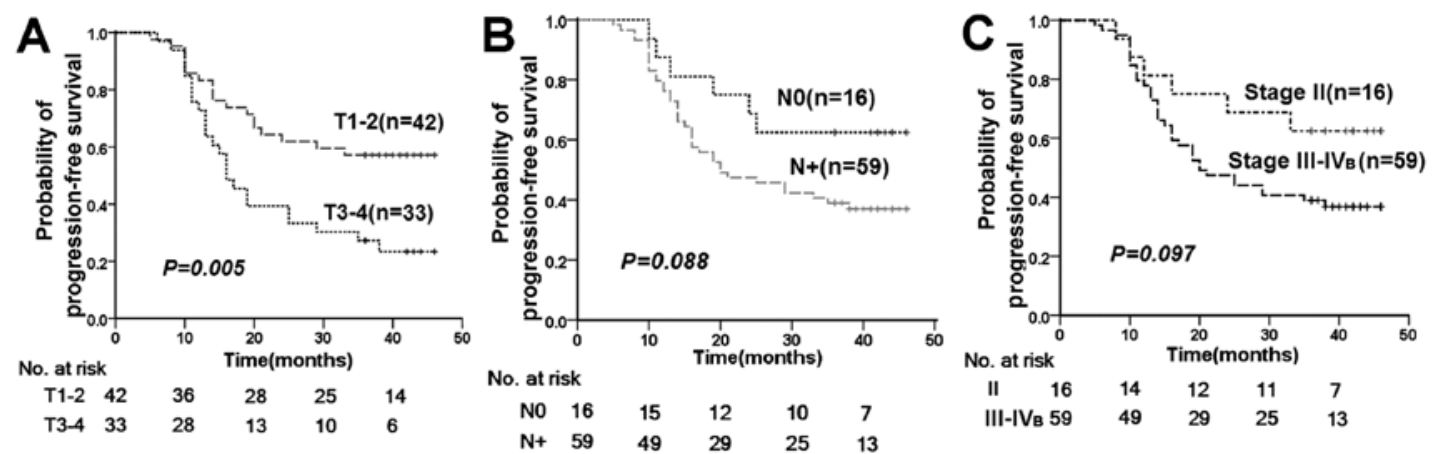

Figure 2. Kaplan-Meier progression-free survival (PFS) curves according to (A) T classification, (B) N classification and (C) overall stage. 
Table III. Association between clinical variables and SNPs of the p53 pathway $\left(\chi^{2}\right.$ analysis) [n $\left.(\%)\right]$.

\begin{tabular}{|c|c|c|c|c|c|c|}
\hline \multicolumn{6}{|c|}{ p53 codon $72 \mathrm{SNP}$} & \multirow[t]{2}{*}{ P-value } \\
\hline \multicolumn{2}{|c|}{ ArgArg } & \multicolumn{2}{|c|}{ Arg/Pro } & \multicolumn{2}{|c|}{ Pro/Pro } & \\
\hline $\mathrm{T} 1-2$ & $\mathrm{~T} 3-4$ & $\mathrm{~T} 1-2$ & T3-4 & $\mathrm{T} 1-2$ & T3-4 & 0.810 \\
\hline $17(40.48)$ & $16(48.48)$ & $19(45.24)$ & $11(33.33)$ & $6(14.29)$ & $6(18.18)$ & \\
\hline No & $\mathrm{N}^{+}$ & No & $\mathrm{N}^{+}$ & NO & $\mathrm{N}^{+}$ & 0.842 \\
\hline $8(50)$ & $25(42.37)$ & $5(31.25)$ & $25(42.37)$ & $3(18.75)$ & $9(15.25)$ & \\
\hline Stage II & Stage III-IV & Stage II & Stage III-IV & Stage II & Stage III-IV & 0.842 \\
\hline $7(43.75)$ & $26(447)$ & $7(43.75)$ & $23(38.98)$ & $2(12.5)$ & $10(16.95)$ & \\
\hline \multicolumn{7}{|c|}{ MDM2 SNP309 } \\
\hline \multicolumn{2}{|c|}{$\mathrm{T} / \mathrm{T}$} & \multicolumn{2}{|c|}{$\mathrm{G} / \mathrm{T}$} & \multicolumn{2}{|c|}{$\mathrm{G} / \mathrm{G}$} & \\
\hline $\mathrm{T} 1-2$ & $\mathrm{~T} 3-4$ & $\mathrm{~T} 1-2$ & $\mathrm{~T} 3-4$ & $\mathrm{~T} 1-2$ & $\mathrm{~T} 3-4$ & $0.001^{\mathrm{a}}$ \\
\hline $10(23.80)$ & $5(15.15)$ & $27(64.29)$ & $10(30.30)$ & $5(11.90)$ & $18(54.55)$ & \\
\hline NO & $\mathrm{N}^{+}$ & NO & $\mathrm{N}^{+}$ & No & $\mathrm{N}^{+}$ & 0.192 \\
\hline $3(18.75)$ & $12(20.34)$ & $5(31.25)$ & $32(54.24)$ & $8(50)$ & $15(25.42)$ & \\
\hline Stage II & Stage III-IV & Stage II & Stage III-IV & Stage II & Stage III-IV & 0.061 \\
\hline $5(31.25)$ & $10(12.5)$ & $9(56.25)$ & $28(47.46)$ & $2(12.5)$ & $21(35.59)$ & \\
\hline \multicolumn{7}{|c|}{ p21 codon 31} \\
\hline \multicolumn{2}{|c|}{ SerSer } & \multicolumn{2}{|c|}{ SerArg } & \multicolumn{2}{|c|}{ ArgArg } & \\
\hline $\mathrm{T} 1-2$ & T3-4 & $\mathrm{T} 1-2$ & $\mathrm{~T} 3-4$ & $\mathrm{~T} 1-2$ & T3-4 & 0.091 \\
\hline $10(25)$ & $16(53.33)$ & $23(57.5)$ & $9(30)$ & 7 (17.5) & $5(16.67)$ & \\
\hline No & $\mathrm{N}^{+}$ & NO & $\mathrm{N}^{+}$ & NO & $\mathrm{N}^{+}$ & 0.131 \\
\hline $9(56.25)$ & $17(31.48)$ & $5(31.25)$ & $27(50)$ & $2(12.5)$ & $10(18.52)$ & \\
\hline Stage II & Stage III-IV & Stage II & Stage III-IV & Stage II & Stage III-IV & 0.419 \\
\hline $4(26.67)$ & $22(40)$ & $8(53.33)$ & $24(43.64)$ & $3(20)$ & $9(16.36)$ & \\
\hline
\end{tabular}

${ }^{a}$ Frequency of the MDM2 SNP309 G allele was significantly higher in more advanced disease (T3-4).
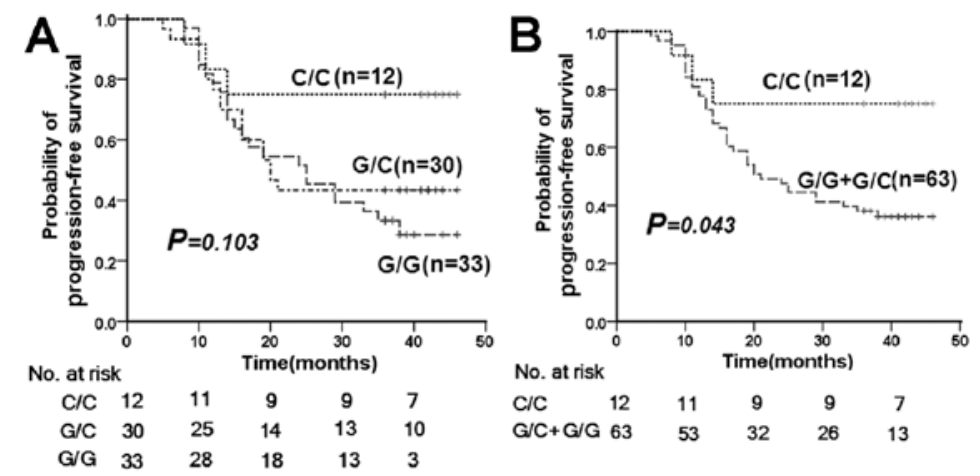

Figure 3. Kaplan-Meier progression-free survival (PFS) curves according to (A) three genotypes and (B) the dominant model of p53 codon 72 SNPs. p53 codon $72 \mathrm{G}$ equivalent to Arg and C equivalent to Pro.

associated with PFS rates (Table IV) after adjustment for age ( $<45$ and $\geq 45$ years), gender (male and female) and concurrent chemotherapy (whether or not administered).
Patients carrying the Pro/Pro p53 codon 72 SNP displayed prolonged PFS when compared with patients with other polymorphic variants (Fig. 3). Multivariate analysis of PFS with 
Table IV. Multivariate analysis of progression-free survival by the Cox proportional hazards model.

\begin{tabular}{lllr}
\hline Variables & \multicolumn{1}{c}{ Subgroups } & HR & 95\% CI \\
\hline T classification & T3-4 vs. T1-2 & 2.683 & $1.430-5.032$ \\
N classification & N $^{+}$vs. N0 & 1.778 & $1.196-2.644$ \\
Smoking status (pack-years) & Ever vs. never & 2.356 & $1.032-5.375$ \\
& $\geq 20$ vs. $<20$ & 2.153 & $1.049-4.416$ \\
& $\geq 30$ vs. $<30$ & 2.899 & $1.349-6.229$ \\
p53 codon 72 SNP & Pro/Pro vs. Arg/Pro+Arg/Arg & 0.300 & $0.092-0.983$ \\
p21 codon 31 SNP & Ser/Ser vs. Ser/Arg+Arg/Arg & 1.411 & $0.697-2.854$ \\
MDM2 SNP309 & T/T vs. T/G+G/G & 0.719 & $0.349-1.479$
\end{tabular}

HR, hazard ratio; CI, confidence interval. Bold numbers indicate statistical significance $(\mathrm{P}<0.05)$.

Table V. Log-rank and proportional hazards analysis (Cox method) for progression-free survival related to the genotype of the p53 pathway and smoking status.

\begin{tabular}{|c|c|c|c|c|c|c|}
\hline \multirow[b]{2}{*}{ Genotypes } & \multirow{2}{*}{$\begin{array}{l}\text { Smoking status } \\
\text { (pack-years) }\end{array}$} & \multicolumn{2}{|l|}{ Log-rank analysis } & \multicolumn{3}{|c|}{ Cox-regression } \\
\hline & & Mean survival time (months) & P-value & HR & $95 \% \mathrm{CI}$ & P-value \\
\hline \multicolumn{7}{|c|}{ p53 codon 72} \\
\hline $\mathrm{C} / \mathrm{C}+\mathrm{G} / \mathrm{C}$ & $<20$ & $30.97 \pm 3.00$ & & 1 & & \\
\hline $\mathrm{G} / \mathrm{G}$ & $<20$ & $31.58 \pm 2.79$ & 0.748 & 1.127 & $0.537-2.366$ & 0.752 \\
\hline $\mathrm{C} / \mathrm{C}+\mathrm{G} / \mathrm{C}$ & $\geq 20$ & $28.42 \pm 4.57$ & & 1 & & \\
\hline $\mathrm{G} / \mathrm{G}$ & $\geq 20$ & $14.78 \pm 3.00$ & 0.012 & 3.590 & $1.219-10.576$ & 0.020 \\
\hline \multicolumn{7}{|c|}{ p21 codon 31} \\
\hline $\mathrm{C} / \mathrm{C}+\mathrm{C} / \mathrm{A}$ & $<20$ & $29.72 \pm 2.35$ & & 1 & & \\
\hline $\mathrm{A} / \mathrm{A}$ & $<20$ & $38.44 \pm 4.07$ & 0.197 & 0.768 & $0.307-1.919$ & 0.572 \\
\hline $\mathrm{C} / \mathrm{C}+\mathrm{C} / \mathrm{A}$ & $\geq 20$ & $24.87 \pm 3.71$ & & 1 & & \\
\hline $\mathrm{A} / \mathrm{A}$ & $\geq 20$ & $11.00 \pm 0.58$ & 0.010 & 6.151 & $1.216-31.116$ & 0.028 \\
\hline \multicolumn{7}{|c|}{ MDM2 309 SNP } \\
\hline $\mathrm{T} / \mathrm{T}+\mathrm{T} / \mathrm{G}$ & $<20$ & $29.81 \pm 2.48$ & & 1 & & \\
\hline $\mathrm{G} / \mathrm{G}$ & $<20$ & $34.35 \pm 3.69$ & 0.329 & 0.659 & $0.280-1.552$ & 0.340 \\
\hline $\mathrm{T} / \mathrm{T}+\mathrm{T} / \mathrm{G}$ & $\geq 20$ & $27.13 \pm 3.90$ & & 1 & & \\
\hline $\mathrm{G} / \mathrm{G}$ & $\geq 20$ & $11.17 \pm 1.85$ & 0.004 & 4.174 & $1.412-12.336$ & 0.010 \\
\hline
\end{tabular}

p53 codon $72 \mathrm{G}$ equivalent to Arg and C equivalent to Pro; p21 codon $31 \mathrm{C}$ equivalent to Ser and A equivalent to Arg. Bold numbers indicate statistical significance $(\mathrm{P}<0.05)$.

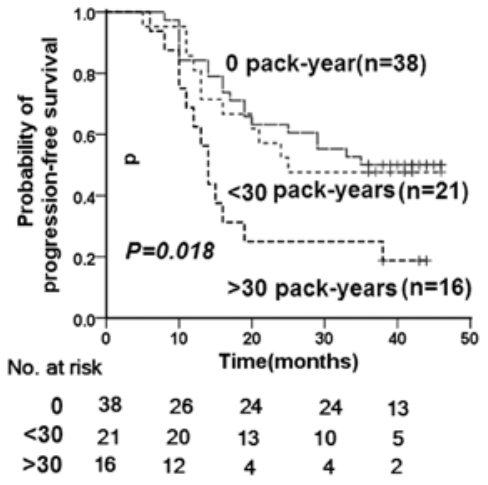

Figure 4. Kaplan-Meier progression-free survival (PFS) curves according to smoking status (cigarette smoking: $0,<30$ and $\geq 30$ pack-years).
Cox proportional hazards model is presented in Table IV. Hazard ratios (HRs) (0.300; 95\% CI, 0.092-0.983; P=0.047) of Pro/Pro p53 codon 72 type for distant metastases and local recurrence were significantly lower after adjustment for age ( $<45$ and $\geq 45$ years), gender, T/N classification and concurrent chemotherapy (whether or not administered). No significant association was evident between MDM2 SNP309 or the p21 codon 31 SNP and susceptibility to PFS, and no combined effects of p53 codon 72, p21 codon 31 and MDM2 309SNP genotypes on risk of progression (recurrence or distant metastases) were observed (data not shown).

Compared with cumulative cigarette smoking of $<20$ pack-years as the reference, the multivariate-adjusted HR (95\% CI) after adjustment for age, gender, $\mathrm{T}$ and 

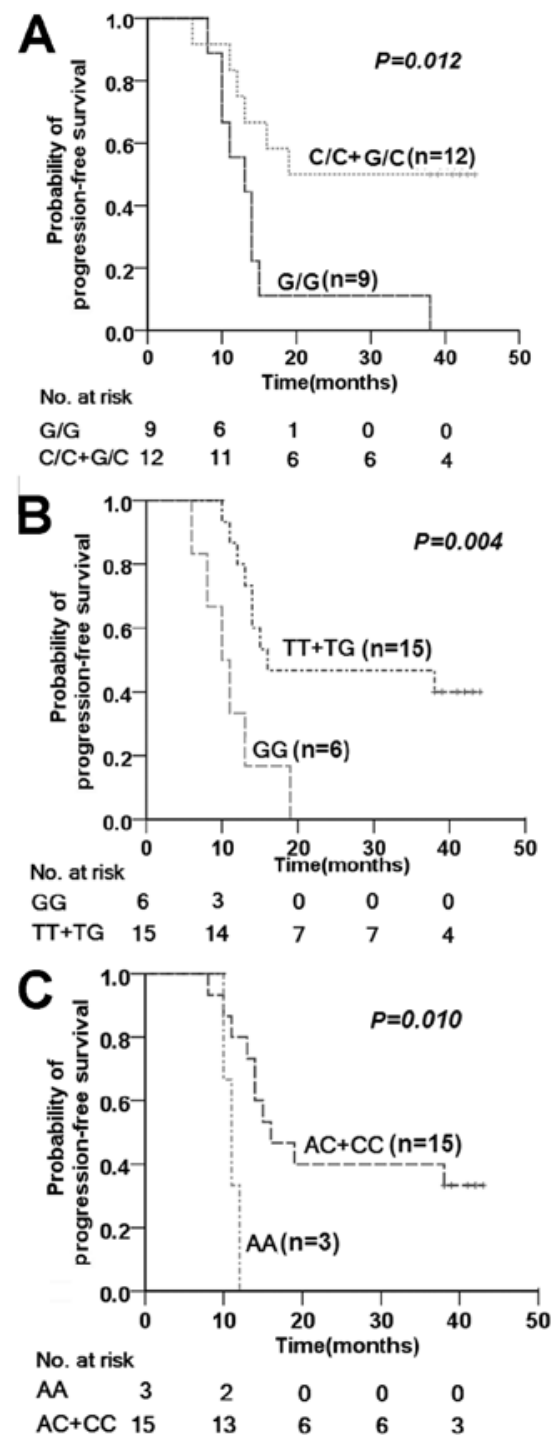

Figure 5. Kaplan-Meier progression-free survival (PFS) curves according to (A) $p 53$ codon $72(\mathrm{G}>\mathrm{C})$, (B) MDM2 SNP309 (T>G), and (C) p21 codon 31 (C $>$ A) polymorphisms for heavy smokers ( $\geq 20$ pack-years) with locoregionally advanced nasopharyngeal carcinoma. p53 codon $72 \mathrm{G}$ equivalent to Arg and $\mathrm{C}$ equivalent to Pro; $\mathrm{p} 21$ codon $31 \mathrm{C}$ equivalent to Ser and A equivalent to Arg.

$\mathrm{N}$ classification and chemotherapy was 2.153 (1.049-4.416; $\mathrm{P}=0.037$ ) for $\geq 20$ pack-years of cumulative cigarette smoking. Comparison of the cumulative cigarette smoking of $\geq 30$ pack-years with $<30$ pack-years revealed an increase in the multivariate-adjusted hazard ratio (95\% CI) to 2.899 (1.349-6.229; $\mathrm{P}=0.006)$. As shown in Fig. 4, smoking status was significantly associated with the time to disease progression $(\mathrm{P}=0.018)$.

Results of the analysis of the combined effects of p53 pathway SNPs and smoking status on the risk of progression (recurrence and distant metastases) are shown in Table V. Subjects with the p53 codon $72 \mathrm{Arg} / \mathrm{Arg}$ genotype were at higher risk of disease progression compared with the other genotypes (HR, 3.590; 95\% CI, 1.219-10.576; $\mathrm{P}=0.020$ ) among the heavy smoker group, as assessed with Cox proportional hazards model (pack-years, $\geq 20$ ). Similar results were observed with the p21 codon $31 \mathrm{Arg} / \mathrm{Arg}$ (HR, 6.151; 95\% CI,
1.216-21.116; $\mathrm{P}=0.028)$ and MDM2 $309 \mathrm{SNP} \mathrm{G} / \mathrm{G}(\mathrm{HR}$, 2.899; 95\% CI, 4.174-12.336; $\mathrm{P}=0.010)$ genotypes. However, among moderate smokers (pack-years, <20), no association was evident between these genotypes and 3-year PFS rates. According to log-rank analysis, mean times to progression for heavy smokers (pack-years, $\geq 20$ ) carrying p53 codon $72 \mathrm{Arg} /$ Arg, p21 codon 31 Arg/Arg, and MDM2 309 SNP G/G genotypes were only $14.78 \pm 3,11.00 \pm 0.58$ and $11.17 \pm 1.85$ months, respectively. These time scales were less than half of those recorded for patients with other genotypes and moderate smokers (pack-years, <20) (Fig. 5).

\section{Discussion}

Multivariate analysis showed that the p53 codon 72 SNP is a useful prognostic factor in patients with locoregionally advanced NPC $(\mathrm{P}=0.047)$. Analysis stratified by smoking status revealed a more significant association between $\mathrm{p} 53$ codon 72 SNP and PFS (P=0.020). Patients with p53 codon 72 Arg/Arg genotype had poorer PFS than those containing other polymorphisms within the heavy smoker group. Two earlier studies proposed that several common mutants of mtp53-codon 72-Arg bind with greater affinity to a p53 family member, the tumor suppressor protein $\mathrm{p} 73$, and inhibit its ability to induce apoptosis $(9,29)$. Among patients with wild-type p53, wtp53-codon 72-Arg was associated with best PFS, while among those containing mutant p53, mtp53codon 72-Pro was associated with best PFS (9). A mutation was distinguished when the mutant signal was $>30 \%$ that of the wild-type allele. Although the p53 gene is rarely mutated in NPC (10), the p53 codon $72 \mathrm{Arg} / \mathrm{Arg}$ genotype presented as an independent predictor of poorer outcomes in the present study, and therefore, the underlying mechanisms require further investigation. Vannini et al (7) provided a molecular explanation for association of the Arg allele with tumor aggressiveness and treatment resistance in advanced breast cancer. The group showed that lower cell death is induced under hypoxia upon transfection of the Arg allele relative to the Pro allele in vitro, which was explained by the finding that the Arg allele upregulates BCRP-I, a hypoxia response gene, which increased treatment resistance.

The MDM2 SNP309 G allele frequency varies among different races. In keeping with other studies, our results showed a $\sim 0.5$ frequency for the $G$ allele in a healthy Chinese population (12), compared with $<0.4$ in Caucasians (30). Although the sample size in our study was small, this difference may partly account for the discrepancies in data in regards to the relationship between tumor progression and MDM2 SNP309. Our experiments demonstrated that MDM2 SNP309 is significantly associated with $\mathrm{T}$ classification, but not $\mathrm{p} 53$ codon 72 SNP and age at onset of NPC (data not shown). The association of MDM2 overexpression with tumor invasiveness and poor survival has been reported in various cancer types, including leiomyosarcoma, astrocytoma, soft tissue sarcoma, pancreatic cancer, melanoma, medulloblastoma and clear cell renal carcinoma (12,31-34). Since the G/G polymorphism is associated with increased MDM2 transcription (30), it is postulated that patients with this polymorphism have poor prognosis. Our data support this hypothesis in the subgroup of heavy smokers ( $\geq 20$ pack-years). Specifically, patients with 
the $\mathrm{G} / \mathrm{G}$ polymorphism had reduced PFS when compared to those with other polymorphisms $(\mathrm{P}=0.010)$. The $\mathrm{G}$ allele of SNP309 was shown to alter the affinity of a well-characterized co-transcriptional activator for multiple hormone receptors, including ER, namely Sp1, consistent with the theory that MDM2 SNP309 may be responsible for increased risk of tumorigenesis, especially in young women (13). However, our overall data showed no association between MDM2 SNP309 and outcomes in NPC, whether or not adjusted for age $(<45$ and $\geq 45$ years) and gender.

P21 plays a direct role in mediating irradiation-induced G1 arrest, with p53 as the transcription factor in this process. Correlation of the gene $\mathrm{p} 21$ codon 31 polymorphism with NPC has been rarely demonstrated. Tsai et al (28) reported that the serine form is predominant in smokers within NPC groups, and the polymorphism may therefore be utilized as a candidate genetic marker for screening NPC risk in association with smoking. We did not observe a significant association between p21 Ser31Arg polymorphism and PFS, either with univariate or multivariate analysis, in overall data. However, as with p53 codon 72 and MDM2 SNP309, the p21 Ser31Arg/Arg genotype may be a predictive factor of poorer outcome of NPC treated with radiotherapy in the heavy smoker group.

Smoking influences the hemoglobin content, owing to the formation of carboxyhemoglobin $(\mathrm{COHb})$ via binding of carbon monoxide (CO). The formation of carboxyhemoglobin causes a left shift in the hemoglobin-oxygen dissociation curve. If other factors remain unchanged, this causes the $\mathrm{pO}_{2}$ to drop to lower levels than normal to release a normal amount of $\mathrm{O}_{2}$ to tissues. Low $\mathrm{pO}_{2}$ values result in decreased diffusion distance from blood vessels and an increase in the fraction of hypoxic cells in tumors. In addition to carboxyhemoglobin formation, smoking may influence the amount of oxygen carried to tissues due to a vasoconstrictive effect of nicotine (35). Owing to the theoretical importance of the tumor oxygenation status on the effectiveness of radiotherapy, there is a compelling biologic rationale for concluding that smoking affects the response to radiotherapy. In the present study, persistent smokers showed higher risk of disease progression, compared to non-smokers (HR, 2.356; 95\% CI, 1.032-5.375; $\mathrm{P}=0.042$ ). Further comparison of groups of smokers between $\geq 20$ and $<20$ pack-years, and $\geq 30$ and $<30$ pack-years revealed an association of poorer PFS of locoregionally advanced NPC with longer and heavier cigarette smoking habit (Table IV and Fig. 4). The most intriguing finding was that associations between p53 pathway SNPs and PFS were more or only significant in the subgroup of heavy smokers ( $\geq 20$ pack-years) (Table V and Fig. 5). Our data strongly advocate that smoking should be avoided to improve the therapeutic efficacy of radiotherapy, particularly for patients carrying SNPs correlated with high risk of local relapse or distant metastasis.

In conclusion, this preliminary study demonstrates for the first time that $\mathrm{p} 53$ codon 72 SNP contributes to locoregionally advanced NPC response to radiotherapy, particularly in patients smoking $\geq 20$ pack-years. Based on the collective findings, we suggest that p53 codon 72 SNP is an independent predictor of outcome for locoregionally advanced NPC treated with radiotherapy. Our data confirmed that smoking has a negative effect on treatment outcomes of cancers. We further showed that the MDM2 SNP309 G/G and p21 codon 31
Arg/Arg genotype are correlated with poorest PFS in heavy smokers ( $\geq 20$ pack-years) among patients with locoregionally advanced NPC treated with radiotherapy.

\section{Acknowledgements}

This study was supported by the Science Foundation for Post Doctorate Research from the China Hunan Provincial Science and Technology Department (no. 2012RS4011), as well as by a Collaboration Project between the Biomedical Engineering Center of Hunan University (China) and Emory-Georgia Tech Nanotechnology Center (USA) (no. 2010DFB30300). We would like to thank Professor Xuping Xi and Professor Junming Luo for their role in the completion of this research.

\section{References}

1. Buchman VL, Chumakov PM, Ninkina NN, Samarina OP and Georgiev GP: A variation in the structure of the protein-coding region of the human p53 gene. Gene 70: 245-252, 1988.

2. Thomas M, Kalita A, Labrecque S, Pim D, Banks L and Matlashewski G: Two polymorphic variants of wild-type p53 differ biochemically and biologically. Mol Cell Biol 19: 1092-1100, 1999.

3. Dumont P, Leu JI, Della Pietra AC III, George DL and Murphy M: The codon 72 polymorphic variants of $\mathrm{p} 53$ have markedly different apoptotic potential. Nat Genet 33: 357-365, 2003.

4. Sullivan A, Syed N, Gasco M, Bergamaschi D, Trigiante G, Attard M, et al: Polymorphism in wild-type p53 modulates response to chemotherapy in vitro and in vivo. Oncogene 23: 3328-3337, 2004.

5. Pim D and Banks L: $\mathrm{p} 53$ polymorphic variants at codon 72 exert different effects on cell cycle progression. Int J Cancer 108: 196-199, 2004.

6. Bergamaschi D, Samuels Y, Sullivan A, Zvelebil M, Breyssens H, Bisso A, et al: iASPP preferentially binds $\mathrm{p} 53$ proline-rich region and modulates apoptotic function of codon 72-polymorphic p53. Nat Genet 38: 1133-1141, 2006.

7. Vannini I, Zoli W, Tesei A, Rosetti M, Sansone P, Storci G, et al: Role of p53 codon 72 arginine allele in cell survival in vitro and in the clinical outcome of patients with advanced breast cancer. Tumor Biol 29: 145-151, 2008.

8. Kim JG, Sohn SK, Chae YS, Song HS, Kwon KY, Do YR, et al: TP53 codon 72 polymorphism associated with prognosis in patients with advanced gastric cancer treated with paclitaxel and cisplatin. Cancer Chemother Pharmacol 64: 355-360, 2009.

9. Bergamaschi D, Gasco M, Hiller L, Sullivan A, Syed N, Trigiante $\mathrm{G}$, et al: $\mathrm{p} 53$ polymorphism influences response in cancer chemotherapy via modulation of $\mathrm{p} 73$-dependent apoptosis. Cancer Cell 3: 387-402, 2003.

10. Lo KW and Huang DP: Genetic and epigenetic changes in nasopharyngeal carcinoma. Semin Cancer Biol 12: 451-462, 2002.

11. Zhuo XL, Cai L, Xiang ZL, Zhuo WL, Wang Y and Zhang XY: TP53 codon 72 polymorphism contributes to nasopharyngeal cancer susceptibility: a meta-analysis. Arch Med Res 40: 299-305, 2009.

12. Bond GL, Hu W, Bond EE, Robins H, Lutzker SG, Arva NC, et al: A single nucleotide polymorphism in the MDM2 promoter attenuates the p53 tumor suppressor pathway and accelerates tumor formation in humans. Cell 119: 591-602, 2004.

13. Bond GL and Levine AJ: A single nucleotide polymorphism in the p53 pathway interacts with gender, environmental stresses and tumor genetics to influence cancer in humans. Oncogene 26: 1317-1323, 2007.

14. Hu Z, Jin G, Wang L, Chen F, Wang X and Shen H: MDM2 promoter polymorphism SNP309 contributes to tumor susceptibility: evidence from 21 case-control studies. Cancer Epidemiol Biomarkers Prev 16: 2717-2723, 2007.

15. Tu HF, Chen HW, Kao SY, Lin SC, Liu CJ and Chang KW: MDM2 SNP 309 and p53 codon 72 polymorphisms are associated with the outcome of oral carcinoma patients receiving postoperative irradiation. Radiother Oncol 87: 243-252, 2008.

16. Chaar I, Arfaoui TA, El Amine el HO, Mahmoud LB, Khiari M, Sammoud S, et al: Impact of MDM2 polymorphism: increased risk of developing colorectal cancer and a poor prognosis in the Tunisian population. Eur J Gastroenterol Hepatol 24: 320-327, 2012. 
17. Zawlik I, Kita D, Vaccarella S, Mittelbronn M, Franceschi S and Ohgaki H: Common polymorphisms in the MDM2 and TP53 genes and the relationship between TP53 mutations and patient outcomes in glioblastomas. Brain Pathol 19: 188-194, 2009.

18. Zhou G, Zhai Y, Cui Y, Zhang X, Dong X, Yang H, et al: MDM2 promoter SNP309 is associated with risk of occurrence and advanced lymph node metastasis of nasopharyngeal carcinoma in Chinese population. Clin Cancer Res 13: 2627-2633, 2007.

19. Sousa H, Pando M, Breda E, Catarino R and Medeiros R: Role of the MDM2 SNP309 polymorphism in the initiation and early age of onset of nasopharyngeal carcinoma. Mol Carcinog 50: 73-79, 2011.

20. Brugarolas J, Chandrasekaran C, Gordon JI, Beach D, Jacks T and Hannon GJ: Radiation-induced cell cycle arrest compromised by p21 deficiency. Nature 377: 552-557, 1995.

21. Deng C, Zhang P, Harper JW, Elledge SJ and Leder P: Mice lacking $\mathrm{p} 21^{\mathrm{CIP1} / \mathrm{WAF} 1}$ undergo normal development, but are defective in G1 checkpoint control. Cell 82: 675-684, 1995.

22. Macleod KF, Sherry N, Hannon G, Beach D, Tokino T, Kinzler K, et al: p53-dependent and independent expression of p21 during cell growth, differentiation, and DNA damage. Genes Dev 9: 935-944, 1995

23. Abbas T and Dutta A: p21 in cancer: intricate networks and multiple activities. Nat Rev Cancer 9: 400-414, 2009.

24. Birgander R, Själander A, Saha N, Spitsyn V, Beckman L and Beckman G: The codon 31 polymorphism of the p53-inducible gene p21 shows distinct differences between major ethnic groups. Hum Hered 46: 148-154, 1996.

25. Su L, Sai Y, Fan R, Thurston SW, Miller DP, Zhou W, et al: P53 (codon 72) and P21 (codon 31) polymorphisms alter in vivo mRNA expression of p21. Lung Cancer 40: 259-266, 2003.

26. Johnson GG, Sherrington PD, Carter A, Lin K, Liloglou T, Field JK and Pettitt AR: A novel type of $\mathrm{p} 53$ pathway dysfunction in chronic lymphocytic leukemia resulting from two interacting single nucleotide polymorphisms within the p21 gene. Cancer Res 69: 5210-5217, 2009.
27. Tan XL, Popanda O, Ambrosone CB, Kropp S, Helmbold I, von Fournier D, et al: Association between TP53 and p21 genetic polymorphisms and acute side effects of radiotherapy in breast cancer patients. Breast Cancer Res Treat 97: 255-262, 2006.

28. Tsai MH, Chen WC and Tsai FJ: Correlation of $\mathrm{p} 21$ gene codon 31 polymorphism and TNF-alpha gene polymorphism with nasopharyngeal carcinoma. J Clin Lab Anal 16: 146-150, 2002.

29. Marin MC, Jost CA, Brooks LA, Irwin MS, O'Nions J, Tidy JA et al: A common polymorphism acts as an intragenic modifier of mutant p53 behaviour. Nat Genet 25: 47-54, 2000.

30. Alhopuro P, Ylisaukko-Oja SK, Koskinen WJ, Bono P, Arola J, Järvinen HJ, et al: The MDM2 promoter polymorphism $\mathrm{SNP} 309 \mathrm{~T} \rightarrow \mathrm{G}$ and the risk of uterine leiomyosarcoma, colorectal cancer, and squamous cell carcinoma of the head and neck. J Med Genet 42: 694-698, 2005.

31. Giordana MT, Duo D, Gasverde S, Trevisan E, Boghi A, Morra I, et al: MDM2 overexpression is associated with short survival in adults with medulloblastoma. Neuro Oncol 4: 115-122, 2002.

32. Haitel A, Wiener HG, Baethge U, Marberger M and Susani M: $\mathrm{Mdm} 2$ expression as a prognostic indicator in clear cell renal cell carcinoma: comparison with p53 overexpression and clinic pathological parameters. Clin Cancer Res 6: 1840-1844, 2000.

33. Polsky D, Melzer K, Hazan C, Panageas KS, Busam K, Drobnjak M, et al: HDM2 protein overexpression and prognosis in primary malignant melanoma. J Natl Cancer Inst 94 1803-1806, 2002.

34. Ranuncolo SM, Varela M, Morandi A, Lastiri J, Christiansen S, Bal de Kier Joffé E, et al: Prognostic value of Mdm2, p53 and p16 in patients with astrocytomas. J Neurooncol 68: 113-121, 2004.

35. Hoff CM, Grau C and Overgaard J: Effect of smoking on oxygen delivery and outcome in patients treated with radiotherapy for head and neck squamous cell carcinoma - a prospective study. Radiother Oncol 103: 38-44, 2012. 